\title{
Retraction Note: Sea water hydrate deposition and coastal enterprise financial management based on $5 \mathrm{G}$ data system
}

\author{
Wenli Zhao $^{1}$
}

Published online: 15 November 2021

C) Saudi Society for Geosciences 2021

Retraction Note to: Arabian Journal of Geosciences (2021) 14: 1598 https://doi.org/10.1007/s12517-021-07755-3

The Editor-in-Chief and the Publisher have retracted this article because the content of this article is nonsensical. The peer review process was not carried out in accordance with the Publisher's peer review policy. The author has not responded to correspondence regarding this retraction.

The original article can be found online at https://doi.org/10.1007/ s12517-021-07755-3

Wenli Zhao

xulei0608@163.com

1 Hunan Financial \& Industrial Vocational-Technical College, Hengyang 421002, Hunan, China 